\title{
The infrared spectra of amine collectors used in the flotation of iron ores
}

\author{
R.M.F. Lima ${ }^{\text {a }}$, P.R.G. Brandao ${ }^{\text {b,* }}$, A.E.C. Peres ${ }^{c}$ \\ ${ }^{a}$ Department of Mining Engineering/UFOP, Ouro Preto, MG, Brazil \\ ${ }^{\mathrm{b}}$ Department of Mining Engineering/UFMG, Rua Espirito Santo 35, sala 702, Belo Horizonte, MG 30160-030, Brazil \\ ${ }^{\mathrm{c}}$ Department of Metallurgical and Materials Engineering/UFMG, Rua Espirito Santo 35, sala 702, Belo Horizonte, MG 30160-030, Brazil
}

Received 13 September 2004; accepted 15 October 2004

\begin{abstract}
Inverse froth flotation is the most used concentration method for itabiritic iron ores, where the quartz gangue is floated, and the iron oxides are kept depressed by starches; medium-chain etheramine acetates are the cationic collectors used. Since there is a lack of thorough studies on the infrared spectroscopy of these reagents (and by other similar techniques), an investigation on the band assignment in the infrared spectra of a typical etheramine acetate was carried out by Fourier-transform infrared spectrometry. To distinguish the bands due to the cationic amine ion from the acetate anion ones, a molecular decyletheramine was also studied, as well as its salts, after some degrees of neutralisation, by acetic or hydrochloric acids; also, potassium acetate was included, to assess the anion bands alone. From this approach, all the significant bands were successfully assigned to the important functional groups in the collector's molecule: $\mathrm{NH}_{x}, \mathrm{CH}_{2}, \mathrm{CH}_{3},-\mathrm{O}-$, and the acetate bands. A confirmation of this method was the identification of the amine cation bands alone, without the presence of the previously associated acetate bands, after adsorption onto the surface of quartz particles, from an aqueous solution of a decyletheramine acetate, at $\mathrm{pH}=10.5$.
\end{abstract}

(C) 2004 Elsevier Ltd. All rights reserved.

Keywords: Iron ores; Flotation reagents; Mineral processing

\section{Introduction}

Froth flotation is the most used concentration method in itabiritic iron ores beneficiation, and it is also extensively used in the processing of similar ores, such as taconites (Hout, 1983; Uwadiale, 1992). In the past, direct flotation methods have been proposed, but presently the one largely employed is the inverse flotation method, in which the quartz gangue is floated, while the iron oxides/hydroxides are kept depressed, with the help of \footnotetext{
1966.

* Corresponding author. Tel.: +55 313238 1967; fax: +55 313238

E-mail address: pbrandao@demin.ufmg.br (P.R.G. Brandao).
}

starches (Iwasaki, 1983; Numela and Iwasaki, 1986). Medium hydrocarbon chain amines (having 10-12 carbon atoms) are the cationic collectors used in iron ore reverse flotation (Iwasaki, 1989; Lima and Brandao, 1999).

Amine solubility in water is very low; so for this reagent to be used successfully, it has to be neutralised (at least partially) by acetic acid, in order to increase its solubility (Leja, 1982; Fuerstenau et al., 1985). This partial neutralisation consists in the formation of a primary amine salt, in which acetate is the anionic radical; the alkyl aminium ion is obviously the cationic counterpart. In order to increase the collector's solubility even further, ether groups have been incorporated into its structure, so the resulting chemical formulae are the following: 


$$
\begin{aligned}
& \Rightarrow \text { alkyl }(\text { decyl }) \text { etheramineacetate } \\
& \quad\left[\mathrm{H}_{3} \mathrm{C}-\left(\mathrm{CH}_{2}\right)_{9}-\mathrm{O}-\left(\mathrm{CH}_{2}\right)_{3}-\mathrm{NH}_{2}\right] \\
& \quad \Rightarrow \text { alkyl }(\text { decyl }) \text { etheramine }
\end{aligned}
$$$$
\left[\mathrm{H}_{3} \mathrm{C}-\left(\mathrm{CH}_{2}\right)_{9}-\mathrm{O}-\left(\mathrm{CH}_{2}\right)_{3}-\mathrm{NH}_{3}{ }^{+}\right]\left[\mathrm{H}_{3} \mathrm{C}-\mathrm{COO}{ }^{-}\right]
$$

Therefore, the collector actually supplied is a mixture of the two species above, and their relative amount is defined by the so-called "degree of neutralisation", which is always referred to as percentages, i.e. $30 \%, 50 \%$, etc.

Although the use of neutralised amines in iron ore processing is common place, there are no thorough studies of these reagents using infrared spectroscopy (neither by means of other similar techniques), so their identification and characterization is not readily done. Some classical textbooks on infrared spectrometry (Nakanishi and Solomon, 1977; Socrates, 1980; Smith, 1999) do assess the band assignment of many amines and related substances, but the above-mentioned specific compounds actually used in quartz gangue flotation in industrial plants have not received the same type of study or the existing information has not been published.

\section{Experimental}

Therefore, an investigation on the bands' assignment in the infrared spectrum of a typical etheramine acetate was carried out by Fourier-transform infrared spectrometry (Giesekke, 1983). An initial problem was to distinguish the bands that could be due to the amine cation and/or to the acetate anion. To overcome this difficulty, the following procedure was obeyed:

(a) the spectrum of the typical alkyl etheramine acetate was recorded; its hydrocarbon chain had mainly 10 carbon atoms;

(b) a molecular (neutral) etheramine, having otherwise the same characteristics of the acetate amine salt, also had its spectrum registered;

(c) this neutral etheramine was reacted with acetic acid, and also with hydrochloric acid, to 10, 20, 30, 40 and $50 \%$ neutralisation degrees, at the temperature of $85^{\circ} \mathrm{C}$. The infrared spectra of the resulting salts were recorded, as well. The use of hydrochloric acid was for comparison purposes, since this compound does not have any important infrared band, occurring at wavenumbers that could interfere with the amine ones, as opposed to acetic acid;

(d) the spectrum of pure potassium acetate $-\left[\mathrm{K}^{+}\right]\left[\mathrm{H}_{3} \mathrm{C}-\right.$ $\mathrm{COO}^{-}$] - was also recorded, to assess the assignment of the anion bands alone.

The transmission technique was used in all cases: $\mathrm{KBr}$ windows in demountable cells for the liquid amine compounds and $\mathrm{KBr}$ pressed pellets for potassium acetate (Chia and Ricketts, 1988). The instrument was a Perkin-Elmer FTIR spectrometer, model 1760-X.

In order to verify the nature of the species adsorbed in the quartz-aqueous solution interface, the following experiment was carried out, and corresponding infrared spectra were recorded:

(a) fine quartz particles (specific surface area $=11.0$ $\mathrm{m}^{2} / \mathrm{g}$ ) were put in contact with an aqueous solution of a commercial grade etheramine acetate collector (the same used in the infrared band assignment tests), with a concentration of $1.14 \times 10^{-2}$ moles/ litre, at $\mathrm{pH}=10.5$;

(b) after contact for $60 \mathrm{~min}$, the particles were separated by filtration, thoroughly rinsed with water at the same $\mathrm{pH}(10.5)$ and dried at room temperature;

(c) $\mathrm{KBr}$ pellets were prepared, containing suitable amounts of these quartz particles, which were expected to carry on their surfaces the adsorbed species.

\section{Results and discussion}

\subsection{Reference spectra and neutralisation studies}

Figs. 1-7 display the spectra recorded for all cases of interest in this study. Fig. 1 is the spectrum of the typical

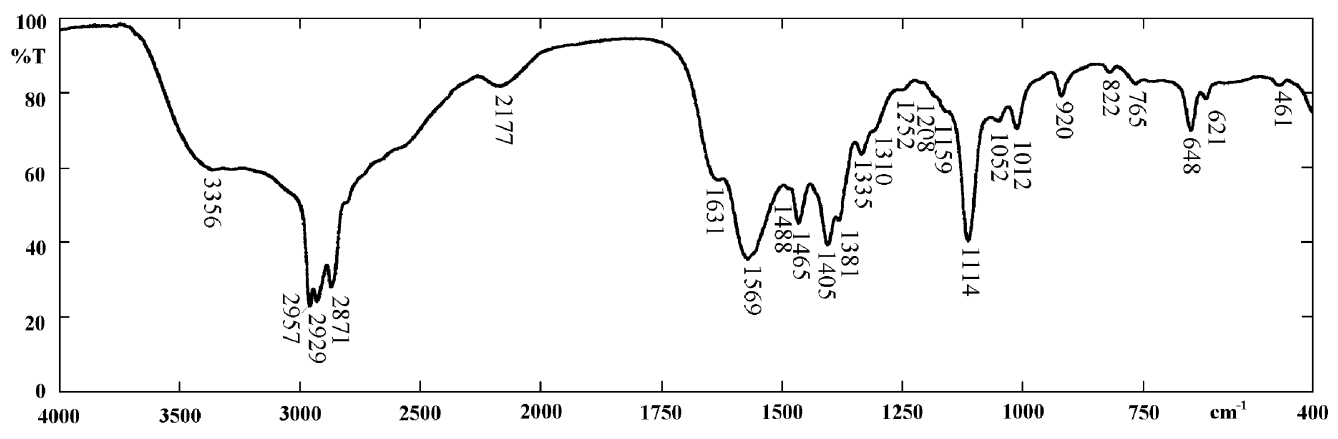

Fig. 1. Infrared transmission spectrum of decyletheramine acetate. 


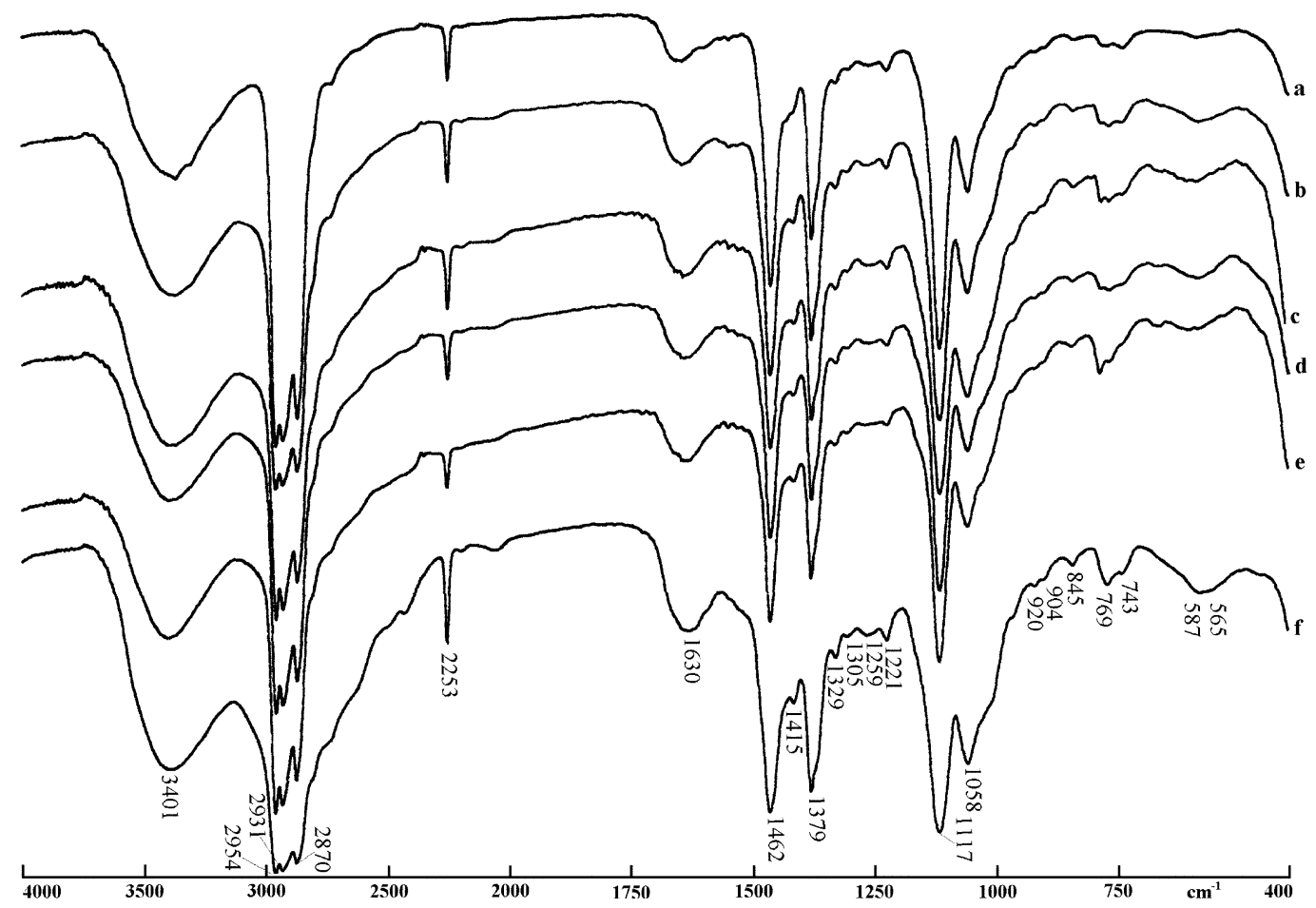

Fig. 2. Neutralisation of the molecular etheramine with hydrochloric acid: infrared transmission spectra (ordinates in \% transmittance): (a) molecular etheramine; (b) etheramine chloride, at 10\%; (c) etheramine chloride, at 20\%; (d) etheramine chloride, at 30\%; (e) etheramine chloride, at $40 \%$; (f) etheramine chloride, at $50 \%$.

commercial decyletheramine acetate, which is the subject of the band assignments and adsorption studies in this investigation. Figs. 2 and 3 show the spectrum of the molecular etheramine and the spectra of the neutralisation products upon reaction with hydrochloric and acetic acids, respectively. Fig. 5 is the spectrum of pure potassium acetate.

Fig. 4 summarizes the results obtained, since it shows the spectra of the original molecular amine and that of the decyletheramine acetate. Between these, are displayed the spectra of the neutralisation products, obtained in this work, with hydrochloric and acetic acid, at the $50 \%$ level.

The main difference between the spectra of the neutralised amines and the spectrum of the original molecular amine is the broadening of the region between 3200 and $2220 \mathrm{~cm}^{-1}$; this is called "the ammonium band" and is diagnostic of the protonation of the former amine, i.e. the formation of an ammonium salt (Nakanishi and Solomon, 1977; Socrates, 1980). As can be observed in Figs. 2 and 3, this peak broadening is gradual according to the degree of neutralisation, but is noticeable even in the $10 \%$ samples. In the $50 \%$ neutralisation spectra it is very conspicuous, despite the superposition with other strong peaks in this spectral region.

The spectra of the original amine and the neutralisation products with hydrochloric acid are remarkably similar (Figs. 2 and 4). The only significant differences are the above mentioned "ammonium band" and a small displacement of the band originally at $1655 \mathrm{~cm}^{-1}$ to $1630 \mathrm{~cm}^{-1}$. This peak is assigned to the bending vibrations of the $\mathrm{NH}_{2}$ group. More than the protonation, the presence of water causes this displacement to shorter wavelengths; the water is introduced by the acid solution used in neutralisation.

The neutralisation with acetic acid (Figs. 3 and 4), in addition to the peaks mentioned above, introduces other bands, mainly in the $1750 \mathrm{~cm}^{-1}$ to $1250 \mathrm{~cm}^{-1}$ range. These bands are possibly due to vibrations of the acetate group and other evidences about this are presented ahead.

By comparing all these spectra, including the potassium acetate spectrum in Fig. 5, it is evident that only two bands can be unambiguously assigned to the etheramine cation, in the important spectral region where the bending vibrations of the $\mathrm{CH}_{2}$ and $\mathrm{CH}_{3}$ groups occur: the peaks at $1465 \mathrm{~cm}^{-1}$ and at $1381 \mathrm{~cm}^{-1}$. Due to the marked difference in chain length between the etheramine (10 +3 carbon atoms) and the short acetate chain (with only a methyl group), these bending vibrations are distinguished. The other bands in the $1750 \mathrm{~cm}^{-1}$ to $1250 \mathrm{~cm}^{-1}$ range and lower wavenumber spectral regions in the etheramine acetate spectrum are assigned to the carboxilate group.

A special case is the sharp band at $1116-1114 \mathrm{~cm}^{-1}$ : it is due to the stretching of the ethereal oxygen $(\mathrm{C}-\mathrm{O}-\mathrm{C})$ 


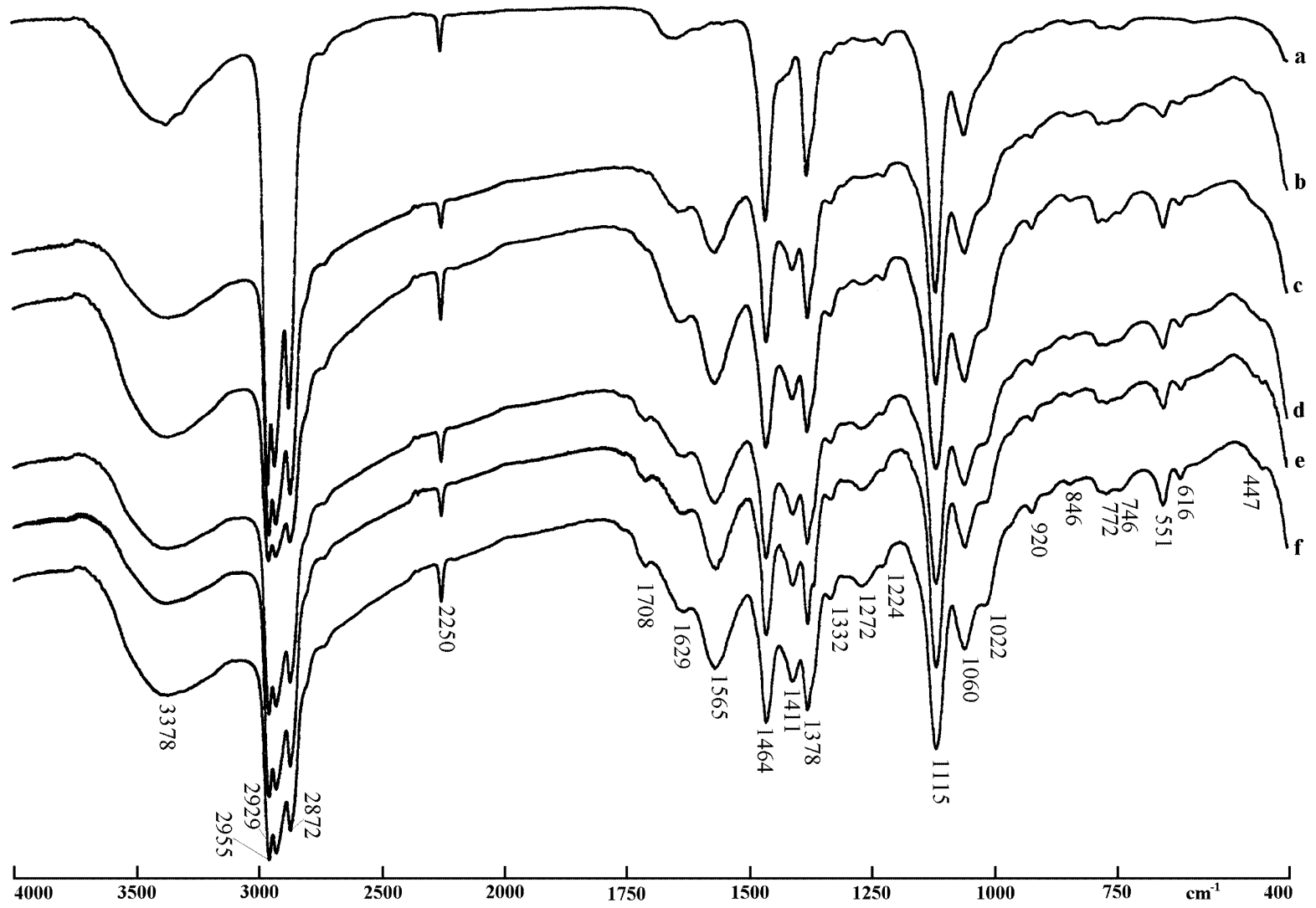

Fig. 3. Neutralisation of the molecular etheramine with acetic acid: infrared transmission spectra (ordinates in \% transmittance): (a) molecular etheramine; (b) etheramine acetate, at 10\%; (c) etheramine acetate, at 20\%; (d) etheramine acetate, at 30\%; (e) etheramine acetate, at 40\%; (f) etheramine acetate, at $50 \%$.

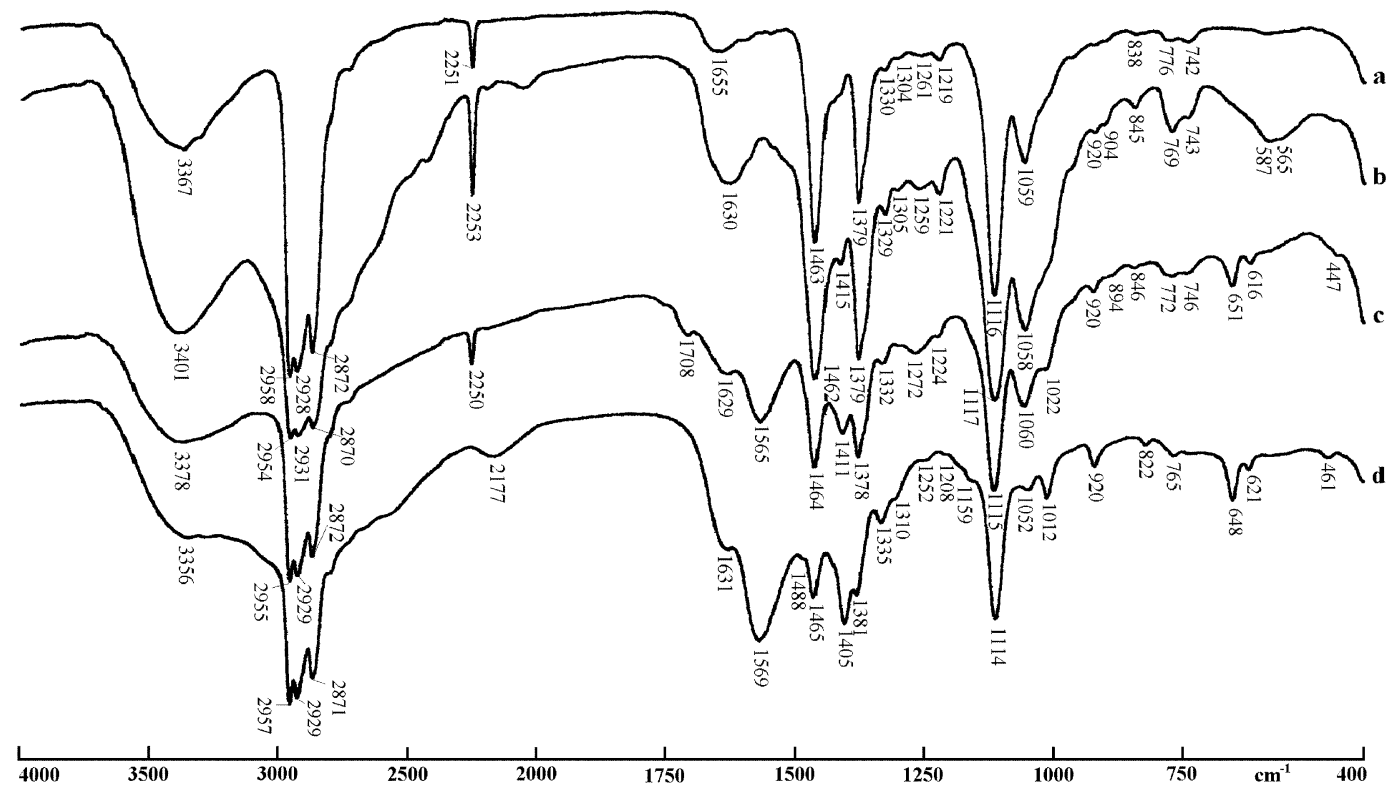

Fig. 4. Infrared transmission spectra (ordinates in \% transmittance): (a) molecular etheramine; (b) etheramine chloride, at 50\%; (c) etheramine acetate, at $50 \%$; (d) commercial etheramine acetate. 


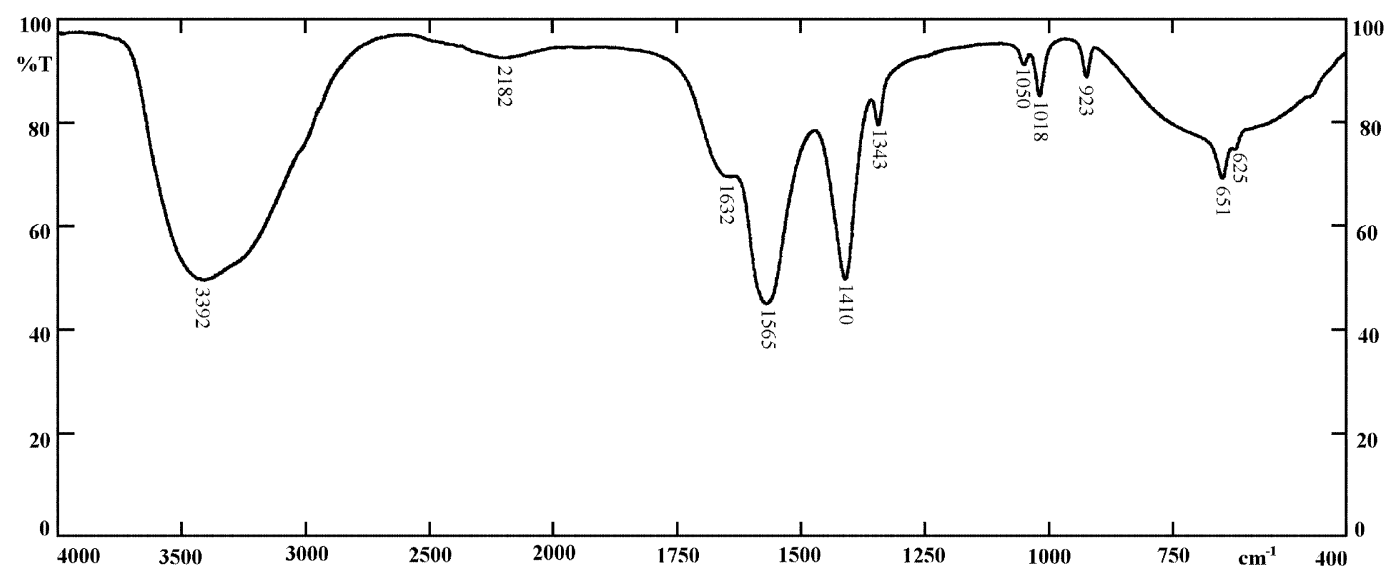

Fig. 5. Infrared transmission spectrum of potassium acetate.

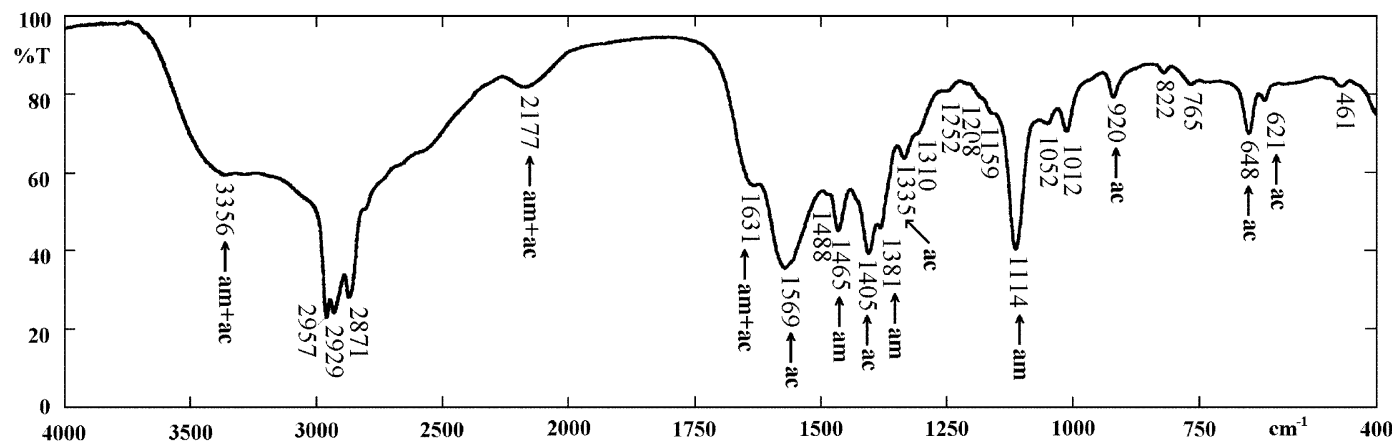

Fig. 6. Infrared transmission spectrum of decyletheramine acetate, showing the assigned bands: am $=$ decyletheramine cation; ac $=$ acetate anion.

group, being therefore diagnostic of the etheramine cation (Papini et al., 2001).

As expected, the group of strong bands between 3000 and $2750 \mathrm{~cm}^{-1}$ are assigned to the stretching vibrations of the $\mathrm{CH}_{2}$ and $\mathrm{CH}_{3}$ groups. Therefore, they are characteristic of the amine cation, but they do not yield any clue on the presence and absence of the acetate anion, as opposed to the ones in the $1700-1250 \mathrm{~cm}^{-1}$ range.

Therefore, etheramine acetate band assignment can be accomplished, with a high degree of confidence, from the results of the present work and from the general data in the literature, in the following way (Nakanishi and Solomon, 1977; Socrates, 1980; Smith, 1999):

- Decyletheramine cation bands: $3356^{*}, 2957,2929$, $2871,1631^{*}, 1465,1381,1114 \mathrm{~cm}^{-1}$.

The ones deserving specific assignment explanation are the following:

$3356 \mathrm{~cm}^{-1} \rightarrow$ undifferentiated stretching of $\mathrm{NH}_{x}$

( ${ }^{*}$ interference with water);

$2957 \mathrm{~cm}^{-1} \rightarrow$ asymmetric stretching of $\mathrm{CH}_{3}$;

$2929 \mathrm{~cm}^{-1} \rightarrow$ asymmetric stretching of $\mathrm{CH}_{2}$;

$2871 \mathrm{~cm}^{-1} \rightarrow$ symmetric stretching of $\mathrm{CH}_{3}$;

$2850 \mathrm{~cm}^{-1} \rightarrow$ symmetric stretching of $\mathrm{CH}_{2}$;
$1631 \mathrm{~cm}^{-1} \rightarrow$ undifferentiated bending of $\mathrm{NH}_{x}$ (* interference with water);

$1465 \mathrm{~cm}^{-1} \rightarrow$ asymmetric bending of $\mathrm{CH}_{3}+$ scissoring (in-plane symmetric bending) of $\mathrm{CH}_{2}$;

$1381 \mathrm{~cm}^{-1} \rightarrow$ symmetric bending of $\mathrm{CH}_{3}$;

$1114 \mathrm{~cm}^{-1} \rightarrow$ stretching of $\mathrm{C}-\mathrm{O}-\mathrm{C}$ (ethereal oxygen).

- Acetate anion bands (see Fig. 5): 1569, 1405, 1335, $1050,1012,648,621 \mathrm{~cm}^{-1}$.

The ones deserving specific assignment explanation are the following:

$1569 \mathrm{~cm}^{-1} \rightarrow$ asymmetric stretching of $\mathrm{COO}^{-}$;

$1405 \mathrm{~cm}^{-1} \rightarrow$ symmetric stretching of $\mathrm{COO}^{-}+$asymmetric bending of $\mathrm{CH}_{3}$;

$1335 \mathrm{~cm}^{-1} \rightarrow$ symmetric bending of $\mathrm{CH}_{3}$.

The asterisk denotes the bands having a high chance of interference by water vibrations: approximately $3356 \mathrm{~cm}^{-1}$, stretching modes; approximately $1631 \mathrm{~cm}^{-1}$, bending modes.

All the other bands appearing in the spectra are not worth special mention because of any of the following reasons: (a) they occur in both spectra of the etheramine and the acetate; (b) they correspond to or are highly influenced by water; (c) they are too small or not reproducible. 


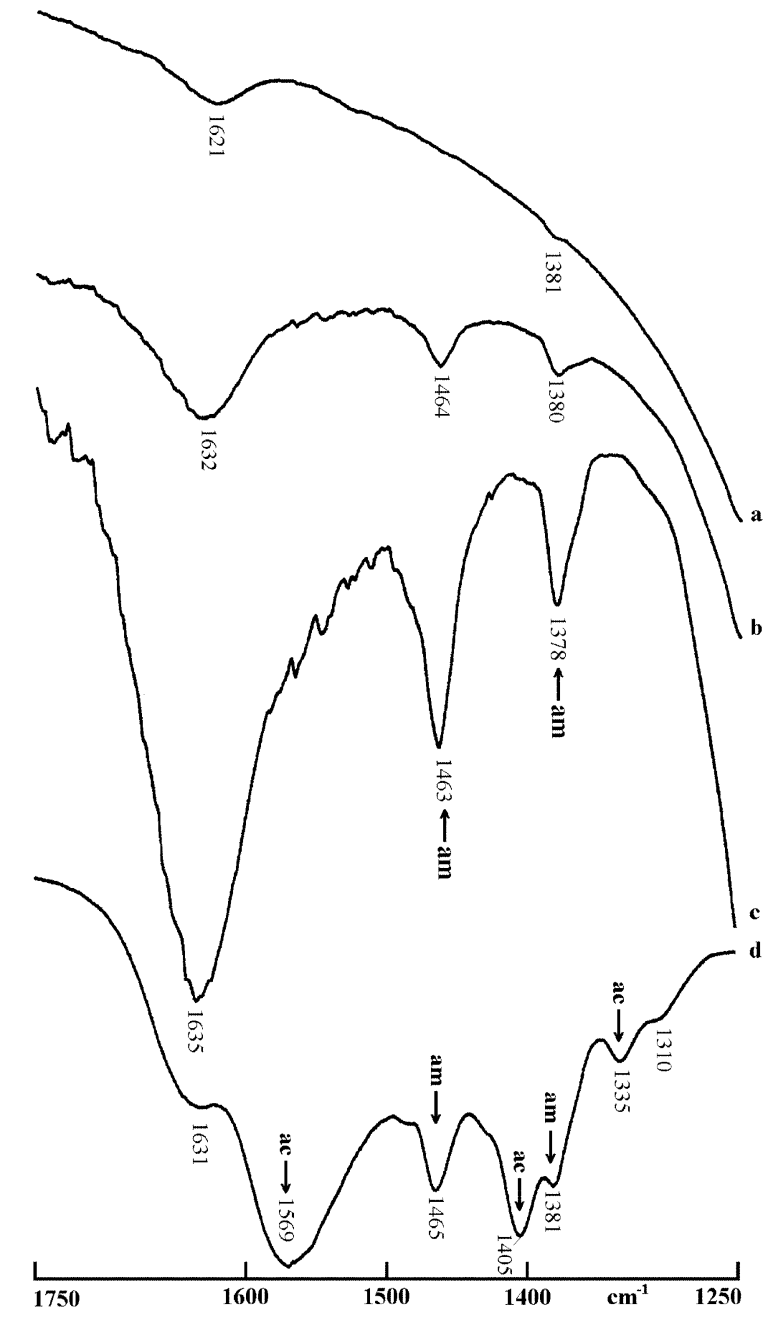

Fig. 7. Infrared transmission spectra (ordinates in $\%$ transmittance): adsorption of decyletheramine acetate onto the quartz surface; (a) original surface; (b) after adsorption; (c) difference spectrum [b-a]; (d) decyletheramine acetate. Assigned bands: $a m=$ decyletheramine cation; ac $=$ acetate anion.

\subsection{Adsorption studies}

An elegant confirmation of the assignment of these diagnostic infrared bands study was obtained from the adsorption tests, as follows (Fig. 7):

(a) in the infrared spectra obtained, clearly defined bands, including the diagnostic peaks of the etheramine cation were observed; the most important of these bands were the ones located at $1463 \mathrm{~cm}^{-1}$ and $1378 \mathrm{~cm}^{-1}$;

(b) no bands assigned to the anionic acetate species could be observed, in the same spectra.

Therefore, these results prove that only the alkyletheramine cations were adsorbed to the quartz substrate. That is exactly what is expected from the currently accepted models of amine cations adsorption onto the quartz surface, which would carry a strong negative charge, at a basic $\mathrm{pH}$ value, such as at $\mathrm{pH}=10.5$, used in the experiments (Iwasaki, 1989). The acetate ion has stayed away from the inner interface region, within the diffuse region of the electric double layer and/or in the bulk solution, thus behaving as an indifferent species (Lima and Brandao, 1999).

\section{Conclusions}

From the comparison with standards and neutralisation approach followed in this investigation, all the significant bands were successfully assigned to the important functional groups in the collector's molecule in their different vibration modes: $\mathrm{NH}_{x}, \mathrm{CH}_{2}, \mathrm{CH}_{3}$, $-\mathrm{O}-$, and the acetate bands.

The important and diagnostic etheramine bands were located at the following positions: $1462 \mathrm{~cm}^{-1}-1465 \mathrm{~cm}^{-1}$, $1378 \mathrm{~cm}^{-1}-1381 \mathrm{~cm}^{-1}$, due to bending vibrations of $\mathrm{CH}_{3}$ and $\mathrm{CH}_{2} ; 1114 \mathrm{~cm}^{-1}-1117 \mathrm{~cm}^{-1}$, due to the vibration of the ethereal oxygen.

The typical acetate bands were positioned at the following frequencies: $1565 \mathrm{~cm}^{-1}-1569 \mathrm{~cm}^{-1}, 1405 \mathrm{~cm}^{-1}$ $1411 \mathrm{~cm}^{-1}, 1012 \mathrm{~cm}^{-1}-1018 \mathrm{~cm}^{-1}, 920 \mathrm{~cm}^{-1}-923 \mathrm{~cm}^{-1}$, $648 \mathrm{~cm}^{-1}-651 \mathrm{~cm}^{-1}$.

Other bands were strong and important, but they were not essentially diagnostic, e.g. the hydrocarbon chain $\mathrm{CH}$ stretching vibrations occurring from $2960 \mathrm{~cm}^{-1}$ to $2870 \mathrm{~cm}^{-1}$, and the NH stretching and bending vibrations at $3400 \mathrm{~cm}^{-1}-3350 \mathrm{~cm}^{-1}$ and $1655 \mathrm{~cm}^{-1}-1630 \mathrm{~cm}^{-1}$, respectively.

An elegant confirmation of this method was the identification of the amine cation bands alone, without the presence of the previously associated acetate bands, after adsorption onto the surface of quartz particles, from an aqueous solution of an amine acetate, at $\mathrm{pH}=10.5$. The acetate ion, therefore, stayed away from the inner interface region, thus behaving as an indifferent species.

\section{Acknowledgments}

The authors are indebted to many companies and individuals for the supply of samples and reagents. They also thank the Brazilian Agencies CNPq and CAPES for the scholarships and financial support.

\section{References}

Chia, L., Ricketts, S., 1988. Basic Techniques and Experiments in Infrared and FT-IR Spectroscopy. Perkin-Elmer Corp, Norwalk.

Fuerstenau, M.C., Miller, J.D., Khun, M.C., 1985. Chemistry of Flotation. SME-AIME, New York.

Giesekke, E.W., 1983. A review of spectroscopic techniques applied to the study of interactions between minerals and reagents in 
flotation systems. International Journal of Mineral Processing 11, 9-56.

Hout, R., 1983. Beneficiation of iron ore by flotation-review of industrial and potential applications. International Journal of Mineral Processing 10, 183-204.

Iwasaki, I., 1983. Iron ore flotation, theory and practice. Mining Engineering 35 (June), 622-631.

Iwasaki, I., 1989. Bridging theory and practice in iron ore flotation. In: Chander, S., Klimpel, R.R. (Eds.), Advances in Coal and Mineral Processing. SME Inc, Littleton, pp. 177-190.

Leja, J., 1982. Surface Chemistry of Froth Flotation. Plenum Press, New York.

Lima, R.M.F., Brandao, P.R.G., 1999. Investigation on the selectivity in the inverse flotation of iron ores by infrared spectrometry. In: Laskowski, J.S. (Ed.), Polymers in Mineral Processing. CIM, Montreal, pp. 139-152.
Nakanishi, K., Solomon, P.H., 1977. Infrared Absorption Spectroscopy, second ed. Holden-Day, San Francisco.

Numela, W., Iwasaki, I., 1986. Iron ore flotation. In: Somasundaran, P. (Ed.), Advances in Mineral Processing. SME Inc, Littleton, pp. 308-342.

Papini, R.M., Brandao, P.R.G., Peres, A.E.C., 2001. Cationic flotation of iron ores: amine characterization and performance. Minerals and Metallurgical Processing 17 (2), 5-9.

Smith, B., 1999. Infrared Spectral Interpretation-A Systematic Approach. CRC Press, Boca Raton.

Socrates, G., 1980. Infrared Characteristic Group Frequencies. WileyInterscience, Chichester.

Uwadiale, G.G.O.O., 1992. Flotation of iron oxides and quartz-a review. Mineral Processing and Extractive Metallurgy Review 11, 129-161. 